\title{
Attitudes of Dermatologic Patients Towards COVID-19 Vaccines: a Questionnaire-Based Survey
}

\author{
Efsun Tanacan ${ }^{1}$ (D) Ogulcan Ibis ${ }^{1} \cdot$ Gulhan Aksoy Sarac $^{1} \cdot$ M. Can Emeksiz ${ }^{1} \cdot$ Didem Dincer $^{1} \cdot$ F. Gulru Erdogan ${ }^{1}$
}

Accepted: 16 August 2021 / Published online: 21 September 2021

(c) The Author(s), under exclusive licence to Springer Nature Switzerland AG 2021

\begin{abstract}
The objective of this paper is to evaluate the attitudes of patients with various dermatologic diseases towards coronavirus disease (COVID-19) vaccines. The present questionnaire-based study was conducted on patients admitted to the outpatient clinic of the Department of Dermatology and Venereology, Ufuk University Hospital, between January 1 and 31, 2021. The study population was divided into two groups based on their ages: $(1)<40$ age group $(n=188)$ and $(2) \geq 40$ age group $(n=111)$, and answers given to 35 specific questions were compared between the groups. The older group had significantly higher levels of anxiety compared to the younger group $(p=0.017)$. Although approximately $60 \%$ of cases in the older group were dedicated to being vaccinated, $40 \%$ of the younger participants were not sure about vaccination $(p<0.001)$. The most frequently demanded vaccine types were the inactivated and mRNA vaccines in the elderly and young groups, respectively $(p<0.001)$. Statistically significant positive weak correlations were observed for age, chronic disease of medication, and presence of severe COVID 19 cases in the environment $(r=0.125 p=0.031, r=0.184 p=0.001, r=0.122 p=0.035$, respectively). Dermatologic patients had generally positive attitudes towards COVID-19 vaccination, and their preferences were affected by age.
\end{abstract}

Keywords COVID-19 $\cdot$ Dermatologic patients $\cdot$ Pandemic $\cdot$ Vaccines

\section{Introduction}

Coronavirus disease 2019 (COVID-19) has been a global healthcare crisis threatening billions of lives for more than a year. It has forced states to take extreme measures like social isolation extensive lockdown and compulsory use of personal protective equipment [1]. Vaccination seems to be the only hope for achieving herd immunity in a reasonably short period of time [2]. However, there are ongoing debates about the efficacy, safety, and possible adverse effects of

This article is part of the Topical Collection on COVID-19

Efsun Tanacan

efsunkln@yahoo.com

1 Department of Dermatology and Venereology, Ufuk University Hospital, Mevlana Bouliard No.: 86-88, 06530 Ankara, Turkey
COVID-19 vaccines [3]. Thus, some parts of the community have concerns related to COVID-19 vaccination [4].

Patients with dermatologic problems are generally susceptible to infections due to altered immunity, frequent use of immunosuppressant medications, and weakness of the skin barrier [5-7]. For this reason, management of risk factors for infectious agents and providing optimal immunity in this population are vital. On the other hand, some dermatologic patients may have concerns about new treatment modalities considering the possible adverse effects of them on their skin diseases. Furthermore, they may be afraid of novel vaccines as the administered immunosuppressive therapies may put them at risk of being infected [8,9].

There are various studies in the literature focusing on the attitudes of patients towards COVID-19 vaccines [2, 10-13]. However, to the best of our knowledge, there is no study evaluating the perspective of dermatologic patients for COVID-19 vaccines.

The aim of the present study is to evaluate the attitudes of patients with various dermatologic diseases towards COVID-19 vaccines. 


\section{Materials and Methods}

The present questionnaire-based study was conducted on patients admitted to the outpatient clinic of the Department of Dermatology and Venereology, Ufuk University Hospital, between January 1 and 31, 2021. A non-validated questionnaire evaluating the attitude of the participants about the COVID-19 vaccine was performed. All patients who gave the required written permission to participate in the study were included. The study protocol was approved by the Turkish Ministry of Health Ankara City Hospital Ethics Committee.

In the first step of the study, data related to the sociodemographic features and clinical characteristics of all participants were recorded. Thereafter answers given to 35 specific questions were recorded. The study population was divided into two groups based on their ages: $(1)<40$ age group and (2) $\geq 40$ age group. Mentioned variables were compared between the two defined groups. Furthermore, a correlation analysis was performed to assess the relationship between vaccination acceptance and various study parameters.

The Statistical Package for the Social Sciences $21 \circledR$ (SPSS 21, IBM Corp. Released 2012. IBM SPSS Statistics for Windows, Version 21.0. Armonk, NY: IBM Corp.) software was used for the statistical analysis. The data was evaluated in terms of normal distribution criteria. Median and interquartile-range values were used for continuous variables, while percentage values were used for categorical variables as the data was not normally distributed. Mann-Whitney $U$ and chi-square tests were conducted for the comparison of variables between the groups. Spearman rho test was performed for the correlation analysis. A type 1 error of 0.05 was claimed statistically significant.

\section{Results}

There were 188 and 111 participants in the $<40$ age and $\geq 40$ age groups, respectively. Distribution of dermatologic diseases among the study population is shown in Table 1. Socio-demographic features, clinical characteristics, and answers to questions of the two groups are compared in Table 2. A wide variety of dermatological diseases have been diagnosed. Significantly lower values for age, rate of smoking, chronic diseases, influenza, and pneumococcal vaccination were observed in the $<40$ age group. On the other hand, $<40$ age group have significantly higher levels of single marital status, education level, loss of work or income, regular exercise rate, and frequency of alcohol consumption $(p<0.005)$.

Comparison of questionnaire answers between the groups is also shown in Table 2. The older group had significantly higher levels of anxiety compared to the younger group $(p=0.017)$. While the younger group preferred the internet and multiple sources, the older group used television more frequently $(p<0.001)$. Although approximately $60 \%$ of cases in the older group were dedicated to being vaccinated, $40 \%$ of the younger participants were not sure about vaccination $(p<0.001)$. While the older group wanted all of the family members to be vaccinated, younger group demanded a more selective approach $(p<0.001)$. While both groups mostly believed that the vaccine would reduce the disease's severity and complications, the older group thought that the vaccine would have their loved ones more frequently $(p<0.001)$. Although the young group was more worried that the vaccine had not been administered to sufficient individuals before, the elderly group was concerned about the vaccine's side effects $(p=0.044)$. The elderly group stated that healthcare workers encouraged them more to be vaccinated compared to the younger group

Table 1 Distribution of dermatologic diseases

\begin{tabular}{|c|c|c|}
\hline Diseases & $n$ & $\%$ \\
\hline $\begin{array}{l}\text { Papulosquamous and eczematous disease (psoriasis, lichen planus, contact dermatitis, seborrheic dermatitis, PLEVA, } \\
\text { parapsoriasis, PLC, pityriasis rosea, atopic dermatitis) }\end{array}$ & 88 & $29.4 \%$ \\
\hline Adnexal disease (acne, rosacea, folliculitis, hidradenitis suppurativa) & 69 & $23.1 \%$ \\
\hline Pruritus & 21 & $7 \%$ \\
\hline Pigmentary disorders & 8 & $2.7 \%$ \\
\hline Hair and Nail diseases & 31 & $10.4 \%$ \\
\hline Infectious diseases & 34 & $11.4 \%$ \\
\hline Benign and malign neoplasm of the skin & 15 & $5 \%$ \\
\hline Urticaria & 20 & $6.7 \%$ \\
\hline Others (bullous diseases, erythema nodosum, panniculitis, vasculitis, Behcet disease, discoid lupus erythematosus) & 13 & $4.3 \%$ \\
\hline
\end{tabular}


Table 2 Comparison of demographic features, clinical characteristics, and answers to questions in the study groups

\begin{tabular}{|c|c|c|c|}
\hline Variables & Group $1(<40$ years $)(n=188)$ & $\begin{array}{l}\text { Group } 2(\geq 40 \text { years }) \\
(n=111)\end{array}$ & $p$ values \\
\hline Age (years) (median, IQR) ${ }^{\mathrm{a}}$ & $29(3)$ & $37(12)$ & $<0.001$ \\
\hline \multicolumn{4}{|c|}{ Gender $(n, \%)^{\mathrm{b}}$} \\
\hline Male & $48(25.5 \%)$ & $40(36.03 \%)$ & \multirow[t]{2}{*}{0.073} \\
\hline Female & $140(74.46 \%)$ & $71(63.9 \%)$ & \\
\hline \multicolumn{4}{|l|}{ Marital status } \\
\hline Single & $161(85.6 \%)$ & $22(19.8 \%)$ & \multirow[t]{2}{*}{$<0.001$} \\
\hline Married & $27(14.4 \%)$ & $89(80.2 \%)$ & \\
\hline \multicolumn{4}{|l|}{ Education level } \\
\hline Primary school & $1(0.5 \%)$ & $23(20.7 \%)$ & \multirow[t]{4}{*}{$<0.001$} \\
\hline Secondary school & $7(3.7 \%)$ & $17(15.3 \%)$ & \\
\hline High school & $37(19.6 \%)$ & $33(29.7 \%)$ & \\
\hline $\begin{array}{l}\text { University and postgradu- } \\
\text { ate }\end{array}$ & $143(76.06 \%)$ & $38(34.2 \%)$ & \\
\hline \multicolumn{4}{|l|}{ Smoking } \\
\hline Yes & $68(36.17 \%)$ & $52(46.8 \%)$ & \multirow[t]{3}{*}{$<0.001$} \\
\hline No & $111(59.04 \%)$ & $41(36.9 \%)$ & \\
\hline Ex-smoker & $9(4.78 \%)$ & $18(16.2 \%)$ & \\
\hline \multicolumn{4}{|c|}{ Frequency of alcohol consumption $(n, \%)$} \\
\hline Never & $103(54.8 \%)$ & $77(69.4 \%)$ & \multirow[t]{3}{*}{0.01} \\
\hline 1-3 times per month & $74(39.4 \%)$ & $25(22.5 \%)$ & \\
\hline 1-5 times per week & $11(5.9 \%)$ & $9(8.1 \%)$ & \\
\hline \multicolumn{4}{|c|}{ Loss of work or income during the pandemic $(n, \%)$} \\
\hline Loss of work & $9(4.8 \%)$ & 0 & \multirow[t]{3}{*}{$<0.001$} \\
\hline Loss of income & $39(20.7 \%)$ & $30(27.0 \%)$ & \\
\hline None & $140(74.5 .0 \%)$ & $81(73.0 \%)$ & \\
\hline \multicolumn{4}{|c|}{ Chronic disease and/or medication $(n, \%)$} \\
\hline Yes & $33(17.6 \%)$ & $59(53 \%)$ & \multirow[t]{2}{*}{$<0.001$} \\
\hline No & $155(84.2 \%)$ & $52(46.8 \%)$ & \\
\hline \multicolumn{4}{|c|}{ Vaccinated for influenza $(n, \%)$} \\
\hline Yes & $3(1.6 \%)$ & $15(13.5 \%)$ & \multirow[t]{2}{*}{$<0.001$} \\
\hline No & $185(98.4 \%)$ & $96(86.5 \%)$ & \\
\hline \multicolumn{4}{|c|}{ Vaccinated for pneumococcus $(n, \%)$} \\
\hline Yes & $3(1.6 \%)$ & $7(6.3 \%)$ & \multirow[t]{2}{*}{0.03} \\
\hline No & $185(98.4 \%)$ & $104(93.7 \%)$ & \\
\hline \multicolumn{4}{|l|}{ Rate of healthy nutrition $(n, \%)$} \\
\hline Yes & $57(30.3 \%)$ & $38(34.2 \%)$ & \multirow[t]{3}{*}{0.37} \\
\hline No & $36(19.1 \%)$ & $26(23.4 \%)$ & \\
\hline Partially & $95(50.6 \%)$ & $47(42.3 \%)$ & \\
\hline \multicolumn{4}{|c|}{ Rate of regular check-ups $(n, \%)$} \\
\hline Yes & $54(28.7 \%)$ & $40(36.1 \%)$ & \multirow[t]{2}{*}{0.19} \\
\hline No & $134(71.3 \%)$ & $71(63.9 \%)$ & \\
\hline \multicolumn{4}{|c|}{ Frequency of regular exercise $(n, \%)$} \\
\hline Not exercise regularly & $100(53.2 \%)$ & $83(74.8 \%)$ & \multirow[t]{5}{*}{0.004} \\
\hline$<1 \mathrm{~h} /$ per week & $20(10.6 \%)$ & $6(5.4 \%)$ & \\
\hline $1-2 \mathrm{~h} /$ per week & $20(10.6 \%)$ & $9(8.1 \%)$ & \\
\hline 2-4 h/per week & $31(16.5 \%)$ & $6(5.4 \%)$ & \\
\hline$>4 \mathrm{~h} /$ per week & $17(9 \%)$ & $7(6.3 \%)$ & \\
\hline
\end{tabular}


Table 2 (continued)

\begin{tabular}{|c|c|c|c|}
\hline Variables & Group $1(<40$ years $)(n=188)$ & $\begin{array}{l}\text { Group } 2(\geq 40 \text { years }) \\
(n=111)\end{array}$ & $p$ values \\
\hline \multicolumn{4}{|c|}{ Previous COVID-19 infection? $(n, \%)$} \\
\hline Yes & $42(22.3 \%)$ & $20(18 \%)$ & \multirow[t]{2}{*}{0.46} \\
\hline No & $146(77.7 \%)$ & $91(82 \%)$ & \\
\hline \multicolumn{4}{|c|}{ Have there been individuals in your environment hospitalized or died in intensive care due to COVID-19 infection? } \\
\hline Yes & $130(69.1 \%)$ & $67(60.3 \%)$ & \multirow[t]{2}{*}{0.15} \\
\hline No & $58(30.9 \%)$ & $44(39.7 \%)$ & \\
\hline \multicolumn{4}{|c|}{ Could you indicate your level of concern about COVID-19 infection (0-10, 0 -no worries, 10 -very worried)? } \\
\hline $0-3$ & $13(6.9 \%)$ & 0 & \multirow[t]{3}{*}{0.017} \\
\hline $4-6$ & $53(28.1 \%)$ & $36(32.4 \%)$ & \\
\hline $7-10$ & $122(64.8 \%)$ & $75(67.6 \%)$ & \\
\hline \multicolumn{4}{|c|}{ What is your level of knowledge about COVID-19 vaccines? } \\
\hline Sufficient & $28(14.9 \%)$ & $15(13.5 \%)$ & \multirow[t]{3}{*}{0.35} \\
\hline Intermediate & $112(59.6 \%)$ & $59(53.2 \%)$ & \\
\hline Insufficient & $48(25.5 \%)$ & $37(33.3 \%)$ & \\
\hline \multicolumn{4}{|c|}{ What source of information do you often use to learn about COVID-19 vaccines? } \\
\hline Internet & $43(22.9 \%)$ & $16(14.4 \%)$ & \multirow[t]{6}{*}{$<0.001$} \\
\hline Television & $18(9.6 \%)$ & $29(26.1 \%)$ & \\
\hline Health professionals & $7(3.7 \%)$ & $6(5.4 \%)$ & \\
\hline Social environment & $13(6.9 \%)$ & $10(9.1 \%)$ & \\
\hline $\begin{array}{l}\text { Internet }+ \text { television }+ \text { writ- } \\
\text { ten press }\end{array}$ & $58(30.9 \%)$ & $29(26.1 \%)$ & \\
\hline $\begin{array}{l}\text { Health profession- } \\
\text { als + internet + televi- } \\
\text { sion + written press }\end{array}$ & $49(26.1 \%)$ & $21(18.9 \%)$ & \\
\hline \multicolumn{4}{|c|}{ Are you considering getting the COVID-19 vaccine? $(n, \%)$} \\
\hline $\begin{array}{l}\text { I am thinking of getting the } \\
\text { COVID-19 vaccine }\end{array}$ & $61(32.4 \%)$ & $65(58.6 \%)$ & \multirow[t]{4}{*}{$<0.001$} \\
\hline $\begin{array}{l}\text { I am thinking of getting the } \\
\text { COVID-19 vaccine if the } \\
\text { vaccine is free }\end{array}$ & $19(10.1 \%)$ & $10(9 \%)$ & \\
\hline Under no circumstances & $32(17.1 \%)$ & $20(18 \%)$ & \\
\hline I have not decided yet & $76(40.4 \%)$ & $16(14.4 \%)$ & \\
\hline \multicolumn{4}{|c|}{ Would you like family members to be vaccinated? $(n, \%)$} \\
\hline No & $66(35.1 \%)$ & $33(29.7 \%)$ & \multirow[t]{3}{*}{$<0.001$} \\
\hline $\begin{array}{l}\text { I would like those aged } 65 \\
\text { and over and those with } \\
\text { chronic diseases to be } \\
\text { vaccinated }\end{array}$ & $55(29.3 \%)$ & $14(12.6 \%)$ & \\
\hline $\begin{array}{l}\text { I would like all family mem- } \\
\text { bers to be vaccinated }\end{array}$ & $67(35.6 \%)$ & $64(57.7 \%)$ & \\
\hline
\end{tabular}

$(p=0.041)$. The most frequently demanded vaccine types were the inactivated and mRNA vaccines in the elderly and young groups, respectively $(p<0.001)$.

Correlation analyses between acceptance of vaccination and various study parameters are shown in Table 3. Statistically significant positive weak correlations were observed for age, chronic disease of medication, and presence of severe COVID-19 cases in the environment ( $r=0.125 p=0.031$, $r=0.184 p=0.001, r=0.122 p=0.035$, respectively).

\section{Discussion}

The majority of the participants in this study showed a positive attitude to COVID-19 vaccines. On the other hand, approximately $40 \%$ of the younger group was hesitant about vaccination. There were also significant demographic clinic and intentional differences between the two groups. Moreover, positive weak/moderate correlations were observed between age, chronic diseases/medications, 
Table 2 (continued)

\begin{tabular}{|c|c|c|c|c|c|}
\hline Variables & \multicolumn{3}{|c|}{ Group $1(<40$ years $)(n=188)$} & $\begin{array}{l}\text { Group } 2(\geq 40 \text { years }) \\
(n=111)\end{array}$ & $p$ values \\
\hline \multicolumn{6}{|c|}{ If you think the vaccine will be beneficial, what factor would you give as the most apparent reason for this? } \\
\hline $\begin{array}{l}\text { I think it will end the pan- } \\
\text { demic }^{a}\end{array}$ & \multicolumn{3}{|c|}{$13(6.9 \%)$} & $19(17.1 \%)$ & \multirow[t]{5}{*}{$<0.001$} \\
\hline $\begin{array}{l}\text { I believe it will effectively } \\
\text { protect my loved ones and } \\
\text { me against illness }{ }^{b}\end{array}$ & \multicolumn{3}{|l|}{$14(7.4 \%)$} & $31(27.9 \%)$ & \\
\hline $\begin{array}{l}\text { I think the vaccine will } \\
\text { reduce the severity and } \\
\text { complications of the } \\
\text { disease }\end{array}$ & \multicolumn{3}{|l|}{$77(41.0 \%)$} & $33(29.7 \%)$ & \\
\hline $\begin{array}{l}\text { I don't think the vaccine } \\
\text { will be helpful }\end{array}$ & \multicolumn{3}{|l|}{$63(33.5)$} & $26(23.4 \%)$ & \\
\hline$a+b$ & \multicolumn{3}{|l|}{$21(11.2 \%)$} & $2(1.8 \%)$ & \\
\hline \multicolumn{6}{|c|}{ How do you think vaccination will affect your current dermatological disease and treatment process? } \\
\hline $\begin{array}{l}\text { I don't think it will have any } \\
\text { effect }\end{array}$ & \multicolumn{3}{|l|}{$94(50 \%)$} & $64(57.6 \%)$ & \multirow[t]{3}{*}{0.18} \\
\hline $\begin{array}{l}\text { I think it will have a nega- } \\
\text { tive effect }\end{array}$ & \multicolumn{3}{|l|}{$22(11.7 \%)$} & $16(14.5 \%)$ & \\
\hline I am indecisive & \multicolumn{3}{|l|}{$72(38.2 \%)$} & $31(27.9 \%)$ & \\
\hline \multicolumn{6}{|c|}{ What is the factor/s that worries you the most about vaccination? } \\
\hline $\begin{array}{l}\text { The vaccine itself could } \\
\text { cause illness }{ }^{a}\end{array}$ & \multicolumn{3}{|c|}{$13(6.9 \%)$} & $7(6.3 \%)$ & \multirow[t]{8}{*}{0.044} \\
\hline Vaccine-related side effects ${ }^{b}$ & \multicolumn{3}{|l|}{$46(24.4 \%)$} & $31(27.9 \%)$ & \\
\hline $\begin{array}{l}\text { It has not been applied to } \\
\text { a sufficient number of } \\
\text { individuals before }\end{array}$ & \multicolumn{3}{|l|}{$28(14.8 \%)$} & $11(9.9 \%)$ & \\
\hline $\begin{array}{l}\text { Concern that the vaccine } \\
\text { may have harmful effects } \\
\text { in the long term }\end{array}$ & \multicolumn{3}{|l|}{$25(13.2 \%)$} & $10(9 \%)$ & \\
\hline The vaccine is ineffective ${ }^{e}$ & \multicolumn{3}{|l|}{$13(6.9 \%)$} & $14(12.6 \%)$ & \\
\hline$a+b+c$ & \multicolumn{3}{|l|}{$12(6.38 \%)$} & $14(12.6 \%)$ & \\
\hline$b+c+d$ & \multicolumn{3}{|l|}{$45(23.9 \%)$} & $24(21.6 \%)$ & \\
\hline$b+e$ & \multicolumn{3}{|l|}{$6(3.1 \%)$} & 0 & \\
\hline \multicolumn{6}{|c|}{ Who would encourage you to be vaccinated? } \\
\hline $\begin{array}{l}\text { Family members and close } \\
\text { friends }\end{array}$ & \multicolumn{3}{|l|}{$20(10.6 \%)$} & $11(9.9 \%)$ & \multirow[t]{6}{*}{0.041} \\
\hline Health workers $^{a}$ & \multicolumn{3}{|l|}{$63(33.5 \%)$} & $56(50.4 \%)$ & \\
\hline Politicians $^{b}$ & \multicolumn{3}{|l|}{$63(33.5 \%)$} & $28(25.2 \%)$ & \\
\hline $\begin{array}{l}\text { With a disease similar to } \\
m e^{c}\end{array}$ & $11(5.8 \%)$ & & & $4(3.6 \%)$ & \\
\hline$a+b$ & $22(11.7 \%)$ & & & $8(7.2 \%)$ & \\
\hline$a+b+c$ & $9(4.7 \%)$ & & & $4(3.6 \%)$ & \\
\hline Which vaccine type/s would & you prefer to & & & & \\
\hline Inactive vaccines (dead-viru & $s$ vaccine $)^{a}$ & $15(7.9 \%)$ & $19(17.1 \%)$ & & $<0.001$ \\
\hline$m R N A$ vaccines $^{b}$ & & $56(29.7 \%)$ & $18(16.2 \%)$ & & \\
\hline Viral vector (adenovirus vac & cines) & $3(1.6 \%)$ & 0 & & \\
\hline I wouldn't prefer any of then & & $54(28.7 \%)$ & $29(26.1 \%)$ & & \\
\hline It does not matter & & $56(29.7 \%)$ & $33(29.7 \%)$ & & \\
\hline$a+b$ & & $4(2.1 \%)$ & $12(10.8 \%)$ & & \\
\hline
\end{tabular}

${ }^{\text {a }}$ Statistical analysis was performed by Mann-Whitney $U$ test

${ }^{\mathrm{b}}$ Statistical analysis was performed by chi-square test

Statistically significant $p$ values were highlighted in bold 
Table 3 Correlation analyses between acceptance of vaccination and various study parameters

\begin{tabular}{lll}
\hline Parameters & $r$ & $p$ \\
\hline Age & 0.125 & $\mathbf{0 . 0 3 1}$ \\
Chronic diseases and medication & 0.184 & $\mathbf{0 . 0 0 1}$ \\
Presence of severe COVID-19 cases in the & 0.122 & $\mathbf{0 . 0 3 5}$ \\
environment & & \\
\hline
\end{tabular}

Statistically significant $p$ values were highlighted in bold

presence of severe COVID-19 cases in the environment, and acceptance of COVID-19 vaccination for both groups.

People all over the world have been under excessive stress since the beginning of the pandemic and COVID-19 vaccines have been at the center of community's attention for months [14]. Although COVID-19 vaccines seem to be the only hope for overcoming this deadly virus, people still have question marks on their heads related to efficacy and safety of the vaccines [15]. The attitudes of people among vaccination were reported to be affected by socio-economic, educational, religious, and personal factors. Furthermore, source of information about the vaccines and experiences of close friends or relatives might also have an impact on people's preferences on vaccination $[10,16,17]$.

The main reason behind the hesitancy of people for COVID-19 vaccination is the limited level of knowledge about the safety and efficacy of these novel vaccines. Generally, it takes years to develop an optimal vaccine for a specific pathogen, however due to the previous experience on other coronaviruses like severe acute respiratory syndrome and Middle East respiratory syndrome. Researches could develop novel types of vaccines for COVID-19 [18, 19]. On the other hand, there are different types of vaccines like inactivated, vector, and mRNA with their specific advantages and limitations $[18,20]$. The most commonly reported adverse effects of COVID-19 vaccines are pain at the injection site, ipsilateral axillary lymph node enlargement, fever, fatigue, and headache. On the other hand, more serious events like anaphylaxis and thrombotic complications were also observed in some vaccine recipients [21, 22]. Thus, people have difficulty in choosing the most appropriate type of COVID-19 vaccine, and they have concerns related to the possibility of being infected by viral particles. Both inactivated and mRNA vaccine platforms are available in Turkey for the time being and people are free to choose between these two vaccine types [13,22].

There are various studies in the literature evaluating the attitude of different populations towards COVID-19 vaccination [23-28] in a questionnaire-based study including 735 students from Italy reported that only $13.9 \%$ of the participants had low intention to vaccinate. On the other hand, no significant differences were found between healthcare students and non-healthcare students [23]. In another study from Israel conducted in 1941, participants indicated that healthcare professionals dealing with severe acute respiratory syndrome coronavirus 2 positive patients were more eager to be vaccinated. Furthermore, rapid development of COVID-19 vaccines was the leading concern among the participants, and a higher hesitancy rate was observed in the nurses compared to the general population [24]. A cross-sectional survey performed on 1000 participants in the USA during the early pandemic period reported that approximately 3 in 10 adults were not sure they would accept vaccination, and 1 in 10 did not intend to be vaccinated [25]. Moreover, according to the results of a study including 5114 participants from the UK, approximately $70 \%$ of the responders were willing to be vaccinated. On the other hand, approximately $12 \%$ of responders were strongly hesitant. Additionally, younger age, female gender, lower income, and ethnicity were found to be associated with hesitancy [26]. Another questionnaire-based survey from China consisted of 1883 participants who revealed that vaccine effectiveness, side effects, and proportion of acquaintances vaccinated were the most important factors for the responders' decision, and approximately $85 \%$ of the responders had a positive attitude towards vaccination. Older participants, individuals with lower educational levels and income, had a higher trust rate for the vaccination. Moreover, participants with higher risk of being infected showed a higher probability to vaccinate [28].

To the best of our knowledge, this is the first study in the literature evaluating the attitude of Dermatologic patients towards COVID-19 vaccination. In our opinion, knowing the perspectives of special populations may help physicians to establish more effective vaccination protocols. Dermatologic patients represent a unique subgroup with higher rate of immunomodulatory medication use and altered immune response [5-7, 29]. COVID-19 provokes both humoral and cell-mediated immunity in the host resulting in an excessive immune response. A cascade of immunologic events leads to an uncontrolled immune-mediated injury in the vital organs in parallel with disease severity. Although our knowledge is limited about the impact of COVID-19 on immunemediated diseases, COVID-19 has potential to worsen their prognosis [30, 31]. Thus mentioned patients population may have different concerns about COVID-19 vaccines. Papulosquamous and eczematous diseases were the most common dermatologic disease among the study population followed by adnexal diseases in the present study. These findings indicated that majority of the patients had chronic diseases necessitating regular treatment protocols. Moreover, mentioned cases had also an altered immunological system.

For this reason, they might have concerns related to their underlying skin diseases. We divided the groups based on their ages considering the possible adverse 
effect of advanced age and higher frequency of coexisting chronic diseases in the elderly population on the course of COVID-19. It has been long known that advanced age is associated with worse disease courses and higher rates of morbidity/mortality [32]. In parallel with this point of view, the older group had higher rates for chronic diseases, influenza, and pneumococcus vaccinations. Furthermore, the older group had lower rates for regular sports activities. Although previous experiences for COVID-19 were similar between the groups, the older group have a higher level of anxiety. Both groups had comparable levels of knowledge about COVID-19 vaccines, yet the source of information was significantly different between the groups. While the younger group mostly preferred the internet as the main source of information, television was the most common information source in the older group. However, healthcare professionals were the least common information source for both groups. Although more than half of the older group were dedicated to vaccination, approximately $40 \%$ of the young participants were hesitant about vaccination.

Additionally, the older group wanted their family members to be vaccinated more commonly. While the older group was more delicate about their environment, the young participants mostly believed that COVID-19 vaccines would reduce disease severity. On the other hand, more than half of both groups thought that COVID-19 vaccines would not affect their dermatologic diseases and treatment process. Fear for vaccines' possible adverse effect was the most common factor about hesitancy for vaccination in both groups. Vaccination of healthcare professionals was the most motivational factor for both groups. Finally, the mRNA vaccine was the most preferred type of COVID-19 vaccine in the present study. These findings were mostly consistent with the current literature [23-28]. However, the present study had strengths like the inclusion of dermatologic patients, high number of study parameters, and the presence of direct correlation analysis for possible affecting factors. Yet, it had some limitations like relatively low number of participants and single-center experience. We believed that the findings of the present study would enlighten the path for the establishment of more effective vaccination programs in dermatologic patients.

In conclusion, dermatologic patients had generally positive attitudes towards COVID-19 vaccination, and their preferences were affected by age.

\footnotetext{
Author Contribution Efsun Tanacan: study design, statistical analysis, manuscript writing.

Ogulcan Ibis: data collection, manuscript writing.

Gulhan Aksoy Sarac: data collection, manuscript writing.

M. Ali Can Emeksiz: data collection, review of the literature.

Didem Dincer Rota: a critical review, study design.

Fatma Gulru Erdogan: supervision, manuscript writing.
}

Availability of Data and Material Yes, it is available.

Code Availability N-A

\section{Declarations}

Ethics Approval The study protocol was approved by the Turkish Ministry of Health Ankara City Hospital Ethics Committee with number E1-21-1522.

Consent to Participate Informed consent was obtained from all patients.

\section{Consent for Publication N-A}

Competing Interests The authors declare no competing interests.

\section{References}

1. Haleem A, Javaid M, Vaishya R. Effects of COVID 19 pandemic in daily life. Curr Med Res Pract. 2020.

2. Paul E, Steptoe A, Fancourt D. Attitudes towards vaccines and intention to vaccinate against COVID-19: implications for public health communications. Lancet Reg Health-Eur. 2021;1:100012.

3. Tregoning JS, Brown ES, Cheeseman HM, Flight KE, Higham SL, Lemm NM, et al. Vaccines for COVID-19. Clin Exp Immunol. 2020;202(2):162-92.

4. Dodd RH, Pickles K, Nickel B, Cvejic E, Ayre J, Batcup C, et al. Concerns and motivations about COVID-19 vaccination. Lancet Infect Dis. 2021;21(2):161.

5. Holcomb ZE, Santillan MR, Morss-Walton PC, Salian P, Her MJ, Giannotti NM, et al. Risk of COVID-19 in dermatologic patients receiving long-term immunomodulatory therapy. J Am Acad Dermatol. 2020;83(4):1215-8.

6. Daeschlein G, von Podewils S, Bloom T, Assadian O, Napp M, Haase $\mathrm{H}$, et al. Risk factors for MRSA colonization in dermatologic patients in Germany. JDDG. 2015;13(10):1015-22.

7. Goldust M, Hartmann K, Abdelmaksoud A, Navarini AA. Utility and risk of dermatologic medications during the COVID-19 pandemic. Dermatol Ther. 2020:e13833.

8. Price KN, Frew JW, Hsiao JL, Shi VY. COVID-19 and immunomodulator/immunosuppressant use in dermatology. J Am Acad Dermatol. 2020;82(5):e173-5.

9. Torres T, Puig L. Managing cutaneous immune-mediated diseases during the COVID-19 pandemic. Am J Clin Dermatol. 2020;21(3):307-11.

10. Wang J, Jing R, Lai X, Zhang H, Lyu Y, Knoll MD, et al. Acceptance of COVID-19 vaccination during the COVID-19 pandemic in China. Vaccines. 2020;8(3):482.

11. Pogue K, Jensen JL, Stancil CK, Ferguson DG, Hughes SJ, Mello EJ, et al. Influences on attitudes regarding potential COVID-19 vaccination in the United States. Vaccines. 2020;8(4):582.

12. Sherman SM, Smith LE, Sim J, Amlôt R, Cutts M, Dasch H, et al. COVID-19 vaccination intention in the UK: results from the COVID-19 vaccination acceptability study (CoVAccS), a nationally representative cross-sectional survey. Hum Vaccines Immunother. 2020:1-10.

13. Goncu Ayhan S, Oluklu D, Atalay A, Menekse Beser D, Tanacan A, Moraloglu Tekin O, et al. COVID-19 vaccine acceptance in pregnant women. Int J Gynecol Obstet. 2021. 
14. Le TT, Andreadakis Z, Kumar A, Román RG, Tollefsen S, Saville M, et al. The COVID-19 vaccine development landscape. Nat Rev Drug Discov. 2020;19(5):305-6.

15. Chou W-YS, Budenz A. Considering emotion in COVID-19 vaccine communication: addressing vaccine hesitancy and fostering vaccine confidence. Health Commun. 2020;35(14):1718-22.

16. Fu C, Wei Z, Pei S, Li S, Sun X, Liu P. Acceptance and preference for COVID-19 vaccination in health-care workers (HCWs). MedRxiv. 2020.

17. Kreps S, Prasad S, Brownstein JS, Hswen Y, Garibaldi BT, Zhang B, et al. Factors associated with US adults' likelihood of accepting COVID-19 vaccination. JAMA Netw Open. 2020;3(10):e2025594-e.

18. Lurie N, Saville M, Hatchett R, Halton J. Developing COVID-19 vaccines at pandemic speed. N Engl J Med. 2020;382(21):1969-73.

19. Yamey G, Schäferhoff M, Hatchett R, Pate M, Zhao F, McDade KK. Ensuring global access to COVID-19 vaccines. Lancet. 2020;395(10234):1405-6.

20. Koirala A, Joo YJ, Khatami A, Chiu C, Britton PN. Vaccines for COVID-19: the current state of play. Paediatr Respir Rev. 2020;35:43-9.

21. Kaur RJ, Dutta S, Bhardwaj P, Charan J, Dhingra S, Mitra P, et al. Adverse events reported from COVID-19 vaccine trials: a systematic review. Indian J Clin Biochem. 2021:1-13.

22. Tanacan E, Ibis O, Aksoy Sarac G, Emeksiz MC, Dincer D, Erdogan FG. The perspectives of dermatology specialists and residents on COVID-19 vaccines: a questionnaire-based survey. Int J Clin Pract. 2021:e14666.

23. Barello S, Nania T, Dellafiore F, Graffigna G, Caruso R. 'Vaccine hesitancy' among university students in Italy during the COVID19 pandemic. Eur J Epidemiol. 2020;35(8):781-3.

24. Dror AA, Eisenbach N, Taiber S, Morozov NG, Mizrachi M, Zigron A, et al. Vaccine hesitancy: the next challenge in the fight against COVID-19. Eur J Epidemiol. 2020;35(8):775-9.
25. Fisher KA, Bloomstone SJ, Walder J, Crawford S, Fouayzi H, Mazor KM. Attitudes toward a potential SARS-CoV-2 vaccine: a survey of US adults. Ann Intern Med. 2020;173(12):964-73.

26. Freeman D, Loe BS, Chadwick A, Vaccari C, Waite F, Rosebrock L et al. COVID-19 vaccine hesitancy in the UK: the Oxford coronavirus explanations, attitudes, and narratives survey (Oceans) II. Psychological medicine. 2020:1-15.

27. Largent EA, Persad G, Sangenito S, Glickman A, Boyle C, Emanuel EJ. US Public Attitudes Toward COVID-19 Vaccine Mandates. JAMA Netw Open. 2020;3(12):e2033324-e.

28. Leng A, Maitland E, Wang S, Nicholas S, Liu R, Wang J. Individual preferences for COVID-19 vaccination in China. Vaccine. 2021;39(2):247-54.

29. Tanacan E, Tanacan A, Fadiloglu E, Unal C, Beksac MS. Psoriasis and pregnancy: retrospective evaluation of 47 pregnancies in a tertiary center. Gynecol Obstet Reprod Med. 2019;25(3):128-32.

30. Felsenstein S, Herbert JA, McNamara PS, Hedrich CM. COVID-19: immunology and treatment options. Clin Immunol. 2020;215:108448.

31. Tanacan A, Yazihan N, Erol SA, Anuk AT, Yetiskin FDY, Biriken $\mathrm{D}$, et al. The impact of COVID-19 infection on the cytokine profile of pregnant women: a prospective case-control study. Cytokine. 2021;140:155431.

32. Izcovich A, Ragusa MA, Tortosa F, Lavena Marzio MA, Agnoletti C, Bengolea A, et al. Prognostic factors for severity and mortality in patients infected with COVID-19: a systematic review. PloS One. 2020;15(11):e0241955.

Publisher's Note Springer Nature remains neutral with regard to jurisdictional claims in published maps and institutional affiliations. 